\title{
Caracterização dos profissionais da linha de frente em um hospital de referência durante a pandemia pelo COVID-19
}

\author{
Characterization of frontline professionals in a referral hospital during the COVID-19 \\ pandemic
}

Caracterización de los profesionales de primera línea en un hospital de referencia durante la pandemia de COVID-19

Josué Rodrigues de Sousa ${ }^{1 *}$, Edna Cristina Vieira Conceição², Lourival Rodrigues Marsola², Naiara Chaves Maia², Gloria Yanne Martins de Oliveira ${ }^{3}$, Juliana Li Ting Matos Sun Barreto ${ }^{3}$, Perla Suely Gaia Raniéri Queiroz ${ }^{3}$, Deyse Cristine dos Santos Costa ${ }^{3}$, Emily Manuelli Mendonça Sena ${ }^{4}$, Danielle Saraiva Tuma dos Reis ${ }^{1,2}$.

\section{RESUMO}

Objetivo: Conhecer como se apresentou a infecção humana pelo SARS-CoV-2 em profissionais da linha de frente de um hospital público durante a pandemia pelo COVID-19. Métodos: Estudo quantitativo, transversal com participação de profissionais das áreas assistenciais em um hospital de referência no atendimento à COVID-19. Resultados: Dos 198 profissionais que participaram, maioria era do sexo feminino entre 30 a 39 anos. Entre as categorias tiveram técnicos de enfermagem (26,8\%), enfermeiros (20,7\%) e médicos $(13,1 \%)$. Todos receberam algum equipamento de proteção individual (EPI), contudo 20,7\% não promovia proteção necessária. $72,2 \%$ recebeu treinamento sobre medidas de proteção, mas $67,7 \%$ relatou ser insuficiente. $71,1 \%$ dos profissionais foram sintomáticos para COVID-19, com relato de cefaléia, mialgia e febre. Os testes realizados apresentaram positividade para TR (67\%), RT-PCR $(72,7 \%)$ e Sorológicos $(78,6 \%)$. O tratamento adotado pelos sintomáticos foi antitérmicos e analgésicos (61,3\%), antibioticoterapia $(59,2 \%)$, corticoides $(26,1 \%)$, Ivermectina $(21,1 \%)$ e Cloroquina ou hidroxicloroquina (15,5\%). Conclusão: A pandemia pelo COVID-19 impõe grandes prejuízos aos serviços de saúde, com exposição dos profissionais ao adoecimento e a falta de oferta do equipamento de proteção individual.

Palavras-chave: Coronavírus, Pessoal de saúde, Equipamento de proteção individual.

\begin{abstract}
Objective: To find out how human infection with SARS-CoV-2 appeared in frontline professionals at a public hospital during the COVID-19 pandemic. Methods: Quantitative, cross-sectional study with the participation of professionals from the care areas in a reference hospital in the service to COVID-19. Results: Of the 198 professionals who participated, most were female between 30 and 39 years old. Among the categories, there were nursing technicians $(26.8 \%)$, nurses $(20.7 \%)$ and doctors $(13.1 \%)$. All received some personal protective equipment, however $20.7 \%$ did not provide necessary protection. $72.2 \%$ received training on protective measures, but $67.7 \%$ reported being insufficient. $71.1 \%$ of professionals were symptomatic for COVID-19, with reports of headache, myalgia and fever. The tests performed were positive for TR (67\%), RT-PCR (72.7\%) and Serological (78.6\%). The treatment adopted by symptomatic patients was antipyretic and analgesic $(61.3 \%)$, antibiotic therapy $(59.2 \%)$, corticosteroids $(26.1 \%)$, Ivermectin $(21.1 \%)$ and Chloroquine or hydroxychloroquine (15.5\%). Conclusion: The COVID-19 pandemic imposes great damage to health services, with exposure of professionals to illness and the lack of provision of personal protective equipment.
\end{abstract}

Keywords: Coronavirus, Health personnel, Personal protective equipment.

\footnotetext{
${ }^{1}$ Universidade Federal do Pará (UFPA), Belém - PA. *E-mail: josuecomt@gmail.com

2 Hospital Universitário Barros João de Barros Barreto (HUJBB), Belém - PA.

${ }^{3}$ Empresa Brasileira de Serviços Hospitalares (EBSERH), Belém - PA.

4 Universidade do Estado do Pará (UEPA), Belém - PA.
} 


\section{RESUMEN}

Objetivo: Conocer cómo apareció la infección humana por SARS-CoV-2 en profesionales de primera línea en un hospital público durante la pandemia de COVID-19. Métodos: Estudio cuantitativo, transversal, con participación de profesionales de las áreas asistenciales en un hospital de referencia en el servicio de COVID19. Resultados: De los 198 profesionales que participaron, la mayoría eran mujeres entre 30 y 39 años. Entre las categorías, estaban los técnicos de enfermería $(26,8 \%)$, enfermeras $(20,7 \%)$ y médicos $(13,1 \%)$. Todos recibieron algo de equipo de protección individual, sin embargo, el $20,7 \%$ no proporcionó la protección necesaria. El 72,2\% recibió formación sobre medidas de protección, pero el $67,7 \%$ informó ser insuficiente. El $71,1 \%$ de los profesionales presentaron síntomas de COVID-19, con informes de cefalea, mialgias y fiebre. Las pruebas realizadas fueron positivas para TR $(67 \%)$, RT-PCR $(72,7 \%)$ y Serológicas $(78,6 \%)$. EI tratamiento adoptado por los pacientes sintomáticos fue antipirético y analgésico (61,3\%), antibioterapia $(59,2 \%)$, corticoides $(26,1 \%)$, ivermectina $(21,1 \%)$ y cloroquina o hidroxicloroquina (15,5\%). Conclusión: La pandemia COVID-19 impone un gran daño a los servicios de salud, con exposición de los profesionales a enfermedades y falta de provisión de equipo de protección personal.

Palabras clave: Coronavirus, Personal de salud, Equipo de protección personal.

\section{INTRODUÇÃO}

Em dezembro de 2019, um novo coronavírus surgiu em Wuhan, China, e causou uma doença respiratória aguda. O Coronaviridae Study Group (CSG) do Comitê Internacional de Taxonomia de Vírus (ICTV) nomeou como a Síndrome Respiratória Aguda Grave de Coronavírus 2 (SARS-CoV-2), posteriormente a doença foi nomeada pela Organização Mundial da Saúde (OMS) como Coronavírus Disease-2019 (COVID-19) (SAHEBNASAGH A, et al., 2020).

Os coronavírus estão relacionados às doenças humanas desde o final da década de 1960, O SARS-CoV2 possui grande patogenicidade e transmissibilidade, maior que o SARS-CoV e da Síndrome Respiratória do Oriente Médio (MERS-CoV). São grandes vírus de RNA de fita simples, envelopados, encontrados além dos humanos em outros animais (cães, gatos, galinhas, gado, porcos e pássaros). Tem diâmetro de $60 \mathrm{~nm}$ a 140 $\mathrm{nm}$ e pontas distintas, variando de $9 \mathrm{~nm}$ a $12 \mathrm{~nm}$, dando aos vírions a aparência de uma coroa solar, são causadores de doenças respiratórias, gastrointestinais e neurológicas, com sintomatologia leve associado ao resfriado comum (POLLARD CA, et al., 2020; HAN Y e YANG H, 2020).

Os coronavírus mais comuns na prática clínica são 229E, OC43, NL63 e HKU1, que geralmente causam sintomas de resfriado comum em indivíduos imunocompetentes. O SARS-CoV-2 é o terceiro coronavírus que causou doença grave em humanos a se espalhar globalmente nas últimas duas décadas (HAN Y e YANG $\mathrm{H}$, 2020; WIERSINGA WJ, et al., 2020).

Atualmente sete cepas de coronavírus humanos foram caracterizadas, dessas quatro são conhecidas por infectar o trato respiratório superior e causar sintomas leves, ao passo que, as outras três são conhecidas por causar doenças graves do trato respiratório inferior, incluindo o SARS-CoV-2. Além disso, como possui afinidade em relação à enzima conversora de angiotensina 2 (ECA2) no intestino e nos rins, pode infectar esses tecidos e penetrar nas fezes, possibilitando a via fecal-oral como possível modo de transmissão. Por meio de recombinação e variação genética, os coronavírus podem se adaptar para infectar novos hospedeiros. Acredita-se que os morcegos sejam um reservatório natural do SARS-CoV-2, mas foi sugerido que os humanos foram infectados com o SARS-CoV-2 por meio de um hospedeiro intermediário, o pangolim (WIERSINGA WJ, et al., 2020; LU R, et al., 2020; LAM TT, et al., 2020; HAN Y e YANG H, 2020).

De acordo com a Agência Nacional de Vigilância Sanitária (ANVISA) a via de transmissão do SARS-CoV2 ocorre de pessoa a pessoa por meio de gotículas respiratórias (expelidas durante a fala, tosse ou espirro) e pelo contato direto com pessoas infectadas ou indireto por meio das mãos, objetos ou superfícies contaminadas, de forma semelhantes com que outros patógenos respiratórios se disseminam. Outra possibilidade de transmissão do vírus, atualmente aceita, se dá por meio de aerossóis (partículas menores e mais leves que as gotículas) gerados durante manipulação direta da via aérea como na intubação orotraqueal ou em outros procedimentos potencialmente geradores de aerossóis. Dessa forma, além das precauções padrão, devem ser implementadas as precauções para contato, precauções para gotículas e as precauções para aerossóis (ANVISA, 2021). 
Segundo a OMS, em todo mundo há mais de 101.5 milhões de casos confirmados até janeiro do presente ano. O continente americano tem a maioria dos casos reportados com mais de 45 milhões, com destaque para os Estados Unidos e o Brasil, que também possuem os maiores números de óbitos pela doença, com mais de 429 e 221 mil, respectivamente (WHO, 2020). O sudeste brasileiro possui o maior número de óbitos, com 84,5 mil. A região norte só tem mais óbitos reportados que o centro oeste com 103.5 mil. Na região norte, o estado do Pará reportou pouco mais de 7,6 mil óbitos (BRASIL, 2020).

A infecção tem o período de incubação de 1 a 14 dias, principalmente de 3 a 7 dias. Um estudo com 181 casos inferiu um período médio de incubação de 5,1 dias e $97,5 \%$ daqueles que desenvolveram sintomas o farão dentro de 11,5 dias (LAUER SA, et al., 2020). Os pacientes com COVID-19 apresentaram sintomas semelhantes, como febre, mal-estar e tosse. A maioria dos adultos ou crianças com infecção por SARS-CoV2 apresentou sintomas gripais leves e alguns pacientes estão em estado crítico e desenvolvem rapidamente síndrome do desconforto respiratório agudo, insuficiência respiratória, falência de múltiplos órgãos e até a morte (GUO YR, et al., 2020).

Em janeiro de 2021, o estado do Amazonas vive o pior momento de enfrentamento da doença, isso se deve ao surgimento de novas linhagens do vírus. De acordo com o Comitê Internacional de Taxonomia de Vírus, este vírus é um novo Betacoronavírus de infecção humana que, com base em sua proximidade genética a dois coronavírus semelhantes a SARS derivados de morcego, provavelmente se originou em morcegos crisântemo. O vírus usa uma proteína spike (S) densamente glicosilada para entrar nas células hospedeiras e se liga com alta afinidade ao receptor da enzima conversora de angiotensina 2 (ACE2) em humanos. A enzima ACE2 é expressa em células alveolares do tipo II. Com o recente surgimento da sub-linhagem P.1, com mutações convergentes na proteína spike (S), levanta preocupação sobre o potencial impacto na infectividade viral. E põe em alerta o restante do país (DEL RIO C e MALANI PN, 2020; PNAVECA F, et al., 2021).

Como parte da atual pandemia de COVID-19, profissionais de saúde em todas as profissões enfrentam grandes desafios para superar a crise. Inúmeros estressores e riscos extraordinários surgem não apenas para a saúde física, mas, para a saúde mental desses profissionais, pois o exercício das atividades laborais e as condições de trabalho passaram a ser fontes potenciais de exposição ao vírus. Há diversos relatos de profissionais e sindicatos denunciando condições de trabalho precarizadas, higiene inadequada, jornadas extenuantes, falta de treinamento e, inclusive, insuficiência ou indisponibilidade de equipamentos de proteção, mesmo nos serviços de terapia intensiva (AMB, 2020).

O Conselho Federal de Enfermagem (COFEN) reporta para essa categoria pouco mais de 45 mil casos e 469 óbitos registrados. Desses, 92 na região norte e 13 no estado do Pará (PETZOLD MB, et al., 2020; COFEN, 2020).

No decorrer da pandemia, profissionais das áreas assistenciais foram afastados por infecção causada pela SARS-CoV-2. Conhecer como os profissionais de saúde foram afetados pela doença, seus sintomas e tratamentos adotados, bem como as condições dadas pela instituição durante este período é o objetivo do presente estudo.

\section{MÉTODOS}

Trata-se de um estudo quantitativo, transversal, realizado em hospital de referência no diagnóstico, tratamento e controle de doenças infecciosas e parasitárias no Estado do Pará. Utilizado técnica de amostragem não probabilística do tipo por conveniência (MARCONI MA e LAKATOS EM, 2017).

Participaram da pesquisa profissionais, residentes médicos e multiprofissionais das áreas assistenciais, que evoluíram ou não com sintomas da COVID-19, independente de testagem. Os profissionais foram convidados por e-mail e aplicativo de troca de mensagem a participar de uma pesquisa on-line, totalmente anônima, onde constava a apresentação, objetivo do projeto e o Termo de Consentimento Livre e Esclarecido. Foi projetado um questionário com perguntas fechadas, disponibilizado na plataforma on-line Google Forms. A coleta online foi realizada no período de setembro a novembro de 2020. 
O instrumento de pesquisa foi disponibilizado com questões referentes ao sexo, idade, fatores de risco, hábitos de vida, além de questões relacionadas à atividade profissional como cargo, tempo de trabalho na instituição, contato com pacientes e colegas suspeitos, uso de EPIs e educação em serviço. A segunda parte do questionário foi disponibilizada apenas para os profissionais que relataram quadro clínico sugestivo de COVID-19, com questões relativas aos sintomas, testagem e tratamento.

Para efeito deste trabalho, os testes sorológicos foram discriminados entre sorológicos, que utilizam ensaios imunoenzimáticos (ELISA), imunoensaios de quimioluminescência (CLIA) e o teste rápido (TR) que utiliza imunocromatografia de fluxo lateral e demonstra apenas de forma qualitativa se o indivíduo tem ou não anticorpos IgM/IgG (VIEIRA LMF, et al., 2020).

Os dados foram armazenados em uma Planilha do Excel, onde foram transformados em tabelas com valores absolutos e percentuais, para sua melhor análise e visualização.

Seguindo a Resolução № 466, de 12 de Dezembro de 2012, o projeto de pesquisa foi aprovado pelo conselho de ética da instituição sob o número CAAE 35042720.9.0000.0017.

\section{RESULTADOS}

Um total de 198 (15,5\%) profissionais de 1278 aceitaram participar da pesquisa e responder o questionário online. Entre os participantes, a maioria foram mulheres (73,7\%), a faixa etária mais frequente foi entre 30 a 39 anos $(37,4 \%), 95(48 \%)$ profissionais praticavam algum tipo de atividade física. Com relação aos fatores de risco, $128(64,6 \%)$ não possuíam, $21(10,6 \%)$ referiram ser obesos, seguidos por $17(8,6 \%)$ asmáticos conforme descrito na Tabela 1.

$\mathrm{Na}$ Tabela 2 podemos identificar as categorias profissionais dos entrevistados, sendo a maioria representada por técnicos de enfermagem com $26,8 \%$, seguidos de enfermeiros com $20,7 \%$ e médicos com $13 \%$ do total. Com relação ao tempo de serviço na instituição, $48 \%$ trabalham de 1 a 3 anos e $26,8 \%$ estão na instituição a menos de um ano. Os locais de atuação dos profissionais foram as unidades de terapia intensiva, unidades clínicas e cirúrgicas e Bloco cirúrgico. $46,5 \%$ dos profissionais possuíam vínculo com outra instituição de saúde.

Tabela 1 - Informações básicas de profissionais das áreas assistenciais.

\begin{tabular}{lcc}
\hline Variável & $\mathbf{n}$ & $\%$ \\
\hline Sexo & 146 & 73,7 \\
\hline Feminino & 52 & 26,3 \\
Masculino & & \\
\hline Faixa Etária (anos) & 35 & 17,7 \\
\hline $20-29$ & 74 & 37,4 \\
$30-39$ & 45 & 22,7 \\
$40-49$ & 39 & 19,7 \\
$50-59$ & 5 & 2,5 \\
$60-69$ & & \\
\hline Hábitos & 95 & 48,0 \\
\hline Atividade física & 19 & 9,6 \\
Etilismo & 3 & 1,5 \\
Tabagismo & 94 & 47,5 \\
Nenhum & & \\
\hline Fatores de Risco & 21 & 10,6 \\
\hline Obesidade & 17 & 8,6 \\
Asma & 13 & 6,6 \\
Cardiopatia & 11 & 5,6 \\
Diabetes & 6 & 3,0 \\
Outras comorbidades & 128 & 64,6 \\
Não se aplica & 198 & 100 \\
\hline Total & & \\
\hline
\end{tabular}

Fonte: Sousa JR, et al., 2021. 
A respeito das medidas de proteção, todos relataram ter recebido algum EPI conforme procedimento em execução. 97,5\% citaram máscara N95 ou PFF2, seguida por touca e luvas. Destes $79,3 \%$ referem que os EPI's promoveram proteção adequada. $72 \%$ receberam algum treinamento a respeito da COVID-19 e paramentação e desparamentação. Sobre a qualidade das ações educativas, $67,7 \%$ relataram ser insuficiente para o desenvolvimento das atividades assistenciais (Tabela 3).

Tabela 2 - Características profissionais.

\begin{tabular}{|c|c|c|}
\hline Variável & $\mathbf{n}$ & $\%$ \\
\hline \multicolumn{3}{|l|}{ Cargo } \\
\hline Tec. enfermagem & 53 & 26,8 \\
\hline Enfermeiro & 41 & 20,7 \\
\hline Médico & 26 & 13,1 \\
\hline Residente multiprofissional & 14 & 7,1 \\
\hline Assistente Social & 11 & 5,6 \\
\hline Fisioterapeuta & 10 & 5,1 \\
\hline Aux. enfermagem & 9 & 4,5 \\
\hline Residente médico & 9 & 4,5 \\
\hline Nutricionista & 9 & 4,5 \\
\hline Psicólogo & 7 & 3,5 \\
\hline Agente Administrativo & 5 & 2,5 \\
\hline Terapeuta ocupacional & 2 & 1,0 \\
\hline Cirurgião dentista & 1 & 0,5 \\
\hline Fonoaudiólogo & 1 & 0,5 \\
\hline \multicolumn{3}{|l|}{ Tempo na instituição } \\
\hline$<1$ ano & 53 & 26,8 \\
\hline 1 a 3 anos & 95 & 48,0 \\
\hline 4 a 6 anos & 4 & 2,0 \\
\hline 7 a 9 anos & 8 & 4,0 \\
\hline 10 anos ou mais & 38 & 19,2 \\
\hline \multicolumn{3}{|c|}{ Trabalha em outra instituição de saúde } \\
\hline Sim & 92 & 46,5 \\
\hline Não & 106 & 53,5 \\
\hline Total & 198 & 100 \\
\hline
\end{tabular}

Fonte: Sousa JR, et al., 2021.

Tabela 3 - Medidas de proteção adotadas pelos profissionais na instituição.

\begin{tabular}{lcc}
\hline Variável & $\mathbf{n}$ & $\%$ \\
\hline Disponibilidade de EPI & 193 & 97,5 \\
\hline Máscara N95 ou PFF2 & 189 & 95,5 \\
Touca & 180 & 90,9 \\
Luvas & 177 & 89,4 \\
Máscaras cirúrgicas & 149 & 75,3 \\
Face-shield & 143 & 72,2 \\
Avental impermeável & 142 & 71,7 \\
Avental permeavel & 139 & 70,2 \\
Óculos de proteção & \multicolumn{2}{c}{} \\
\hline Os EPI promovam a proteção necessária & 157 & 79,3 \\
\hline Sim & 41 & 20,7 \\
Não & & \\
\hline Recebeu treinamento & 143 & 72,2 \\
\hline Sim & 55 & 27,8 \\
Não & \multicolumn{2}{c}{32,3} \\
\hline Treinamentos oferecidos foram suficientes & 64 & 67,7 \\
\hline Sim & 134 & 100 \\
\hline Não & 198 & \\
\hline Total
\end{tabular}

Fonte: Sousa JR, et al., 2021. 
Dentre os participantes, 142 (71,7\%) apresentaram algum sintoma sugestivo de COVID-19. Enquanto que $56(28,3 \%)$ não tiveram sintomas, e não estão contabilizados nos resultados seguintes. A Tabela 4 mostra que $69 \%$ dos entrevistados acreditam ter sido infectados no hospital. Dentre os sintomas mais frequentes temos cefaléia $(63,4 \%)$, mialgia $(58,5 \%)$, febre $(57,7 \%)$ e tosse $(56,3 \%)$, e menos frequente náuseas e vômitos.

A Tabela 5 nos mostra o tipo de testagem e seus respectivos resultados. Foram realizadas 100 testagens rápidas, destas $67 \%$ foram positivas. Com relação à sorologia para anticorpos $\mathrm{lgM}$, foram realizados 23 testes com positividade em $72,7 \%$ delas. 22 testes RT-PCR, foram coletados, com resultado positivo em $72,7 \%$. 17 profissionais não realizaram qualquer tipo de testagem.

Com relação aos tratamentos realizados para o COVID-19, 61,3\% relataram fazer uso de antitérmicos e analgésicos, 59,2\% realizaram antibioticoterapia e $26,1 \%$ fizeram uso de corticoide. O uso de ivermectina foi realizado por $21,1 \%$ e $15,5 \%$ dos participantes relataram ter utilizado cloroquina ou hidroxicloroquina. $10,6 \%$ não realizaram qualquer tipo de tratamento. 50,7\%, referiram ter recebido atendimento médico no hospital. $4,2 \%$ dos participantes sintomáticos necessitaram de internação hospitalar, sendo que 1,4\% foram admitidos em UTI (Tabela 6).

Tabela 4 - Sintomas relatados pelos profissionais.

\begin{tabular}{lcc}
\hline Variável & $\mathbf{n}$ & $\%$ \\
\hline Onde acredita que foi infectado & & \\
\hline No hospital & 98 & $69,0 \%$ \\
Comunidade & 26 & $18,3 \%$ \\
Outra unidade de saúde & 18 & $12,7 \%$ \\
\hline Sintomas & & \\
\hline Cefaleia (dor de Cabeça) & 90 & $63,4 \%$ \\
Mialgia (dor muscular) & 83 & $58,5 \%$ \\
Febre & 82 & $57,7 \%$ \\
Tosse & 80 & $56,3 \%$ \\
Adinamia (fraqueza) & 79 & $55,6 \%$ \\
Anosmia (Perda de olfato) & 78 & $54,9 \%$ \\
Dor de garganta & 73 & $51,4 \%$ \\
Ageusia ( perda de paladar) & 64 & $45,1 \%$ \\
Coriza & 63 & $44,4 \%$ \\
Diarreia & 60 & $42,3 \%$ \\
Dispnéia & 59 & $41,5 \%$ \\
Lombalgia & 52 & $36,6 \%$ \\
Artralgia (dores na articulação) & 47 & $33,1 \%$ \\
Dor abdominal & 26 & $18,3 \%$ \\
Outro & 23 & $16,2 \%$ \\
Náuseas e Vômitos & 8 & $5,6 \%$ \\
\hline Total & 142 & 100 \\
\hline
\end{tabular}

Fonte: Sousa JR, et al., 2021.

Tabela 5 - Tipo e resultado dos testes para COVID-19 realizados pelos profissionais. Belém, Pará, 2020.

\begin{tabular}{lccc} 
Exame Laboratorial & Resultado Positivo (\%) & Resultado Negativo (\%) & Total n (\%) \\
\hline Teste Rápido & $67(67)$ & $33(33)$ & $100(70,4)$ \\
Sorologia IgG & $22(78,6)$ & $6(21,4)$ & $28(19,7)$ \\
Sorologia IgM & $14(60,9)$ & $9(39,1)$ & $23(16,2)$ \\
RT-PCR & $16(72,7)$ & $6(27,3)$ & $22(15,5)$ \\
Não realizou testagem & & & $17(12,0)$ \\
\hline
\end{tabular}

Fonte: Sousa JR, et al., 2021. 
Tabela 6 - Tratamento realizado pelos profissionais sintomáticos pelo COVID-19.

\begin{tabular}{lcc}
\hline Variável & $\mathbf{n}$ & $\%$ \\
\hline Tratamento & & \\
\hline Antitérmico/ Analgésico & 87 & $61,3 \%$ \\
Antibioticoterapia & 84 & $59,2 \%$ \\
Corticoide & 37 & $26,1 \%$ \\
Ivermectina & 30 & $21,1 \%$ \\
Cloroquina/ Hidroxicloroquina & 22 & $15,5 \%$ \\
Não realizou tratamento & 15 & $10,6 \%$ \\
Trombolíticos & 9 & $6,3 \%$ \\
Oxigenoterapia & 5 & $3,5 \%$ \\
Nitazoxanida (Annita) & 5 & $3,5 \%$ \\
Suplementação com vitaminas & 3 & $2,1 \%$ \\
ASS & 3 & $2,1 \%$ \\
Hidratação & 2 & $1,4 \%$ \\
Tamiflu & 1 & $0,7 \%$ \\
\hline Atendimento no hospital & \multicolumn{2}{c}{} \\
\hline Sim & 72 & $50,7 \%$ \\
Não & 70 & $49,3 \%$ \\
\hline Internação Hospitalar & \multicolumn{2}{c}{} \\
\hline Sim & 6 & $4,2 \%$ \\
Não & 136 & $95,8 \%$ \\
\hline Internação em UTI & 2 & $1,4 \%$ \\
\hline Sim & 142 & 100 \\
\hline Total & \multicolumn{2}{c}{} \\
\hline
\end{tabular}

Fonte: Sousa JR, et al., 2021.

\section{DISCUSSÃO}

O perfil do público que participou da presente pesquisa corrobora com o estudo de Hernandes ESC, et al. (2017), onde, segundo ele, os profissionais de saúde brasileiros são, em sua maioria, formados por mulheres, jovens, maiores de 30 anos.

Dos entrevistados, apenas $48 \%$ praticavam alguma atividade física, dado este também confirmado por Crochemore-Silva I, et al. (2020). De acordo com Lim MA e Pranata R (2020), o sedentarismo está relacionado com a falta de atividade física, obesidade, síndrome metabólica e envelhecimento com diminuição das defesas imunológicas. A adoção de um estilo de vida fisicamente ativo pode atrasar o envelhecimento do sistema imunológico e minimizar o risco de contrair doenças transmissíveis e não transmissíveis. Além de reduzir o risco de síndrome do desconforto respiratório agudo, uma das principais causas de morte em pacientes com COVID-19 (NYENHUIS SM, et al., 2020).

Os fatores de risco da população em estudo não foram tão expressivos, assim como relatado em uma pesquisa chinesa, onde $25,1 \%$ apresentou alguma comorbidade, com prevalência de hipertensão seguida por cardiopatias e diabetes (GUAN WJ, et al., 2020). Valores semelhantes foram encontrados por Huang C, et al. (2020).

A obesidade foi relatada entre os entrevistados e citada por Rychter AM, et al. (2020), que cita as características que a relacionam com a COVID-19, dentre elas, a resposta imunológica desregulada, inflamação crônica, desequilíbrio do endotélio, disfunção metabólica e suas comorbidades associadas relacionadas à obesidade. Além disso, os tecidos adiposos obesos com a doença superexpressam os receptores para a entrada do SARS-CoV-2 (RITTER A, et al., 2020).

Um estudo italiano avaliou a relação entre a gravidade da COVID-19 e as classes de obesidade de acordo com o índice de massa corpórea (IMC). Como resultado, evidenciou-se uma maior necessidade de ventilação mecânica invasiva ou não invasiva e uma maior admissão em unidades de terapia intensiva ou semi-intensiva nos pacientes com sobrepeso e obesidade (BUSETTO L, et al., 2020). 
Entre os profissionais entrevistados prevaleceu a equipe de enfermagem, com realização de procedimentos de risco $(62,6 \%)$. Entre os trabalhadores da saúde, enfermeiros, técnicos de enfermagem e auxiliares de enfermagem representam maioria nos serviços públicos e privados, sendo essenciais e considerados nucleares na estrutura das profissões da saúde (SOUZA LPS e SOUZA AG, 2020).

Para Ağalar C e Egin DO (2020), há um maior risco envolvendo procedimentos geradores de aerossóis, como intubação, extubação e procedimentos relacionados; procedimentos post-mortem envolvendo dispositivos de alta velocidade; indução de escarro; alguns procedimentos dentários, oxigênio nasal de alto fluxo e ressuscitação cardiopulmonar. No mais, neste estudo não pedimos para os profissionais relatarem qual desses procedimentos realizaram.

Outro fator que influencia na possibilidade de infecção da equipe, diz respeito à experiência profissional do colaborador na instituição, com a adoção e execução dos protocolos preconizados. Nesse sentido, podemos observar que $48 \%$ dos participantes estão vinculados à unidade de um a três anos. $O$ que pode ser justificado pela contratação emergencial realizada pela instituição no decorrer da pandemia, a fim de vencer a falta de profissionais, devido ao alto número de colaboradores afastados. Somado a isto, temos também os residentes médicos e multiprofissionais que estão em formação, exercendo treinamento em serviço, também responderam ao questionário e permanecem pouco tempo na instituição.

A exposição dos profissionais à pacientes e colegas suspeitos ou confirmado por COVID-19 identificado no presente estudo também é ilustrado por Jin YH, et al. (2020), segundo o qual mais da metade da equipe infectada teve contato próximo com pacientes confirmados ou suspeitos em seu departamento ou ambiente de trabalho antes de saberem o diagnóstico do paciente.

Como se trata de uma doença de transmissão muito rápida, promover a proteção do profissional da linha de frente demonstra ser um grande desafio. A instituição deve prover EPl's adequados, com orientações claras sobre o uso, criando e favorecendo o apoio logistico no fornecimento não só de EPl's como de equipamentos médicos, ajustando rotinas e educando os colaboradores, priorizando a paramentação e desparamentação do equipamento, conforme foi ofertado para os profissionais em questão, (Ağalar C e Egin DO, 2020).

A importância de treinamentos na utilização do EPI é demonstrada em pesquisa realizada na Etiópia com 368 profissionais de saúde, que demonstrou o baixo nível do uso correto de EPI's por profissionais de saúde em um hospital, porém, esses valores aumentam quando comparado, os colaboradores que receberam treinamento para tal com os colegas que não receberam (TEKALEGN Y, et al., 2020).

Outro estudo foi realizado com 143 profissionais de saúde da linha de frente na Índia. Constatou-se que apenas $44,1 \%$ do total de participantes havia realizado treinamento prévio para manuseio de EPI, o que contrasta com o nosso resultado $(79,3 \%)$ (OJHA S, et al., 2020). Outro fator importante listado por Jin YH, et al (2020) é a escassez de EPI que poderá contribuir para intensificar o medo da exposição ao coronavírus no trabalho e contribuir para o sofrimento psicológico ou outras doenças.Portanto, o fornecimento estável e adequado de EPI é altamente recomendado, mesmo em períodos sem pandemia.

Dos 142 funcionários, 69\% acreditam ter contraído a infecção na instituição, seguido pelos que citam a comunidade como fonte de infecção (18,3\%). Em estudo semelhante, Jin YH, et al (2020), relata que 84,5\% dos casos presumiram que foram infectados no ambiente de trabalho, $4,9 \%$ acreditam ter se infectado na comunidade.

Em relação aos sintomas comuns relatados pelos profissionais acometidos pelo COVID-19, como febre $(83,6 \%)$, tosse $(82,5 \%)$ e dispneia $(74,3 \%)$, seguidos de desconforto respiratório $(65,6 \%)$, e dor de garganta $(26,8 \%)$ os mesmos são encontrados em outros estudos como o do Sistema de Informação de Vigilância da Gripe - SIVEP-Gripe (DUARTE MMS, et al., 2020; JIN YH, et al., 2020; HUANG C, et al., 2020).

Com relação aos testes diagnósticos, a maioria realizou o teste de triagem para detectar anticorpos do Sars-CoV-2 (TR) e os resultados foram positivos ou reagentes, com valores acima de $60 \%$ em todas as formas de testagem, seja TR, RT-PCR ou sorológicos, semelhante ao encontrado no estudo de coorte dinamarquês, que utilizou teste rápido em profissionais de saúde, demonstrando uma soroprevalência maior naqueles que atuam em unidades especificas para COVID-19 (IVERSEN K, et al., 2020). 
Vale ressaltar que, o resultado do teste rápido, de forma isolada, não pode ser usado como diagnóstico da COVID-19, deve ser utilizado para fins de triagem, auxílio diagnóstico e acompanhamento imunológico e epidemiológico da doença. Mesmo o RT-PCR, preconizado pela OMS como forma de diagnóstico laboratorial não exclui o diagnóstico, mesmo quando negativo (XU Y, et al., 2020).

Por fim, com relação ao tratamento adotado pelos profissionais sintomáticos, os antitérmicos e analgésicos $(61,3 \%)$ foram os mais utilizados o que contrasta com estudo realizado com 54 médicos em Wuhan que optaram por terapia antiviral (100\%), antibioticoterapia (57.4\%) e altas doses de corticoide $(35.2 \%)$ (CHU J, et al., 2020). Apesar disto, a população pesquisada teve baixo índice de internação $(4,2 \%)$ com pouquíssimos casos sob assistência de terapia intensiva $(1,4 \%)$ diferente do mencionado por Ranzani OT, et al. (2021), quanto à gravidade da doença com uma mortalidade hospitalar de 38\%, internação em UTI de $59 \%$ e necessidade de ventilação mecânica em $80 \%$.

\section{CONCLUSÃO}

O estudo apresentou algumas limitações, dentre elas o tamanho da amostra. A pandemia da COVID-19 impõe grandes desafios aos serviços de saúde, como a obtenção de insumos, EPI e a complexidade da doença. A maioria dos profissionais da linha de frente no combate ao vírus é formada por mulheres jovens com mais de um vínculo de trabalho. A obesidade mostrou-se o fator de risco frequente. Mesmo com o fornecimento de EPIs e as capacitações acerca da doença, a maioria apresentou sintomas no decorrer da pandemia. Recomenda-se que novos estudos sejam desenvolvidos, tendo em vista o aprofundamento dos aspectos tratados e descritos neste artigo.

\section{REFERÊNCIAS}

1. AĞALAR C, EGIN DO. Protective measures for COVID-19 for healthcare providers and laboratory personnel. Turkish Journal of Medical Sciences, 2020; 50(3): 578-584.

2. ANVISA. Agência Nacional de Vigilância Sanitária. Nota técnica GVIMS/GGTES/ANVISA no 04/2020. Orientações para serviços de saúde: medidas de prevenção e controle que devem ser adotadas durante a assistência aos casos suspeitos ou confirmados de infecção pelo novo coronavírus (sars-cov-2) - (atualizada em 27/10/2020). Disponível em: https://www.gov.br/anvisa/pt-br/centraisdeconteudo/publicacoes/servicosdesaude/notastecnicas/nota_tecnica_gvims_ggtes_anvisa_04_2020_reviso_27-10-2020.pdf. Acesso em: 11 mar. 2021.

3. AMB. ASSOCIAÇÃO MÉDICA BRASILEIRA. 2020. Faltam EPIs em todo o país. São Paulo. Disponível em: https://amb.org.br/epi/. Acesso em: 11 abr. 2021.

4. BRASIL. Ministério da Saúde. Secretaria de Vigilância em Saúde. Painel Coronavírus. 2020. Disponível em: https://covid.saude.gov.br/. Acesso em: 20 dez. 2020.

5. BUSETTO L, et al. Obesity and COVID-19: An Italian Snapshot. Obesity (Silver Spring), 2020; 28(9): 1600-1605.

6. CHU J, et al. Clinical characteristics of 54 medical staff with COVID-19: A retrospective study in a single center in Wuhan, China. Journal of Medical Virology, 2020; 92(7): 807-13.

7. COFEN. Conselho Federal de Enfermagem. 2020. Disponível em: http://www.cofen.gov.br/. Acesso em: 23 dez. 2020.

8. CROCHEMORE-SILVA I, et al. Prática de atividade física em meio à pandemia da COVID-19: estudo de base populacional em cidade do sul do Brasil. Ciência \& Saúde Coletiva, 2020; 25(11): 4249-4258.

9. DEL RIO C, MALANI PN. COVID-19-New Insights on a Rapidly Changing Epidemic. JAMA, 2020; 323(14): 13391340.

10. DUARTE MMS, et al. Descrição dos casos hospitalizados pela COVID-19 em profissionais de saúde nas primeiras nove semanas da pandemia, Brazil, 2020. Epidemiologia e Serviço de Saúde, 2020; 29(5):1-8.

11. GUAN WJ, et al. Comorbidity and its impact on 1590 patients with Covid-19 in China: A Nationwide Analysis. European Respiratory Journal 2020, 2020. Disponível em: https://erj.ersjournals.com/content/early/2020/03/17/13993003.005472020. Acesso em: 12 dez. 2020.

12. GUO YR, et al. The origin, transmission and clinical therapies on coronavirus disease 2019 (COVID-19) outbreak - an update on the status. Military Medica Research, 2020; 7(11): 1-10.

13. HAN Y, YANG H. The transmission and diagnosis of 2019 novel coronavirus infection disease (COVID-19): A Chinese perspective. Journal Of Medica Virology, 2020; 92(6): 639-644.

14. HERNANDES ESC, et al. Perfil Socioeconômico e Epidemiológico dos Trabalhadores do Ministério da Saúde do Brasil. Comunicação em Ciências da Saúde, 2017; 28(3/4): 303-312.

15. HUANG C, et al. Clinical features of patients infected with 2019 novel coronavirus in Wuhan, China. Lancet, 2020; 395(10223): 497-506.

16. IVERSEN K, et al. Risk of COVID-19 in health-care workers in Denmark: an observational cohort study. The Lancet Infectious Diseases, 2020; 20(12): 1401-1408. 
17. JIN YH, et al. Perceived infection transmission routes, infection control practices, psychosocial changes, and management of COVID-19 infected healthcare workers in a tertiary acute care hospital in Wuhan a cross-sectional survey. Military Medica Research, 2020; 7(24): 1-13.

18. LAUER SA, et al. The Incubation Period of Coronavirus Disease 2019 (COVID-19) From Publicly Reported Confirmed Cases: Estimation and Application. Annals of Internal Medicine, 2020; 10: M20-0504.

19. LIM MA, PRANATA R. The Danger of Sedentary Lifestyle in Diabetic and Obese People During the COVID-19 Pandemic. Clinical Medicine Insights Endocrinol Diabetes, 2020; 13: 1-2.

20. MARCONI MA, LAKATOS EM. Fundamentos de Metodologia Científica. 8aㅡ Edição. São Paulo: Atlas, 2017.

21. NYENHUIS SM, et al. Exercise and Fitness in the Age of Social Distancing During the COVID-19 Pandemic. The Journal of Allergy and Clinical Immunology: In Practice, 2020; 8(7): 2152-2155.

22. NAVECA F, et al. SARS-CoV-2 reinfection by the new Variant of Concern (VOC) P.1 in Amazonas, Brazil. Virological.org, 2021. Disponível em: https://virological.org/t/sars-cov-2-reinfection-by-the-new-variant-of-concern-vocp-1-in-amazonas-brazil/596. Acesso em: 24 jan. 2021.

23. OJHA S, et al. Knowledge of Handling the Personal protective equipment (PPE) by frontline Allied Health professionals in COVID-19 outbreak - A Web-based Survey Study. Journal of Radiology Nursing, 2020. Disponível em: https://pesquisa.bvsalud.org/controlecancer/resource/pt/mdl-33390860?src=similardocs. Acesso em: 10 out. 2020.

24. PETZOLD MB, et al. Dealing with psychological distress by healthcare professionals during the COVID-19 pandemia. Nervenarzt, 2020; 91: 417-42.

25. POLLARD CA, et al. A pandemia COVID-19: uma crise de saúde global. Physiological genomics, 2020; 52(11): 549557.

26. LAM TT, et al. Identifying SARS-CoV-2-related coronaviruses in Malayan pangolins. Nature, 2020; 583: $282-285$.

27. LU R, et al. Genomic characterisation and epidemiology of 2019 novel coronavirus: implications for virus origins and receptor binding. Lancet, 2020; 395(10224): 565-574.

28. RANZANI OT, et al. Characterisation of the first 250000 hospital admissions for COVID-19 in Brazil: a retrospective analysis of nationwide data. The Lancet Respiratory Medicine, 2021; 9: 407-418.

29. RITTER A, et al. Obesity and COVID-19: Molecular Mechanisms Linking Both Pandemics. International Journal of Molecular Sciences, 2020; 21(16): 5793.

30. RYCHTER AM, et al. Should patients with obesity be more afraid of COVID-19?. Obesity Reviews, 2020; 21 (9): 1-8.

31. SAHEBNASAGH A, et al. Tratamentos farmacológicos de COVID-19. Pharmacological Reports, 2020; 72(6): 14461478.

32. SOUZA LPS, SOUZA AG. Enfermagem brasileira na linha de frente contra o novo Coronavírus: quem cuidará de quem cuida? Journal of nursing and health, 2020; (n.esp.): e20104005.

33. TEKALEGN Y, et al. Correct Use of Facemask Among Health Professionals in the Context of Coronavirus Disease (COVID-19). Risk Management and Healthcare Policy, 2020; 13: 3013-3019.

34. VIEIRA LMF, et al. COVID-19 - Laboratory Diagnosis for Clinicians. An updating article. Escola Paulista de Medicina da Universidade Federal de São Paulo, São Paulo (SP), Brazil, São Paulo Med. J. 2020. Disponível em: https://preprints.scielo.org/index.php/scielo/preprint/view/411. Acesso em: 12 set. 2020.

35. XU Y, et al. Current approaches in laboratory testing for SARS-CoV-2. s. Internatinal Journal of Infectious Diseases, 2020; 100: 7-9.

36. WHO. World Health Organization. Painel do WHO Coronavirus Disease (COVID-19) Dashboard. 2020. Disponível em: https://covid19.who.int/. Acesso em: 20 de dez. 2020.

37. WIERSINGA WJ, et al. Pathophysiology, Transmission, Diagnosis, and Treatment of Coronavirus Disease 2019 (COVID-19): A Review. JAMA, 2020; 324(8): 782-793. 